\title{
Circulating tumor cells: hope to diagnose and treat metastatic cancer
}

\author{
Pravin D. Potdar \\ Department of Molecular Medicine and Biology, Jaslok Hospital and Research Centre, Mumbai 400026, India.
}

Correspondence to: Dr. Pravin D. Potdar, Department of Molecular Medicine and Biology, Jaslok Hospital and Research Centre, Mumbai 400026, India. E-mail: ppotdar@jaslokhospital.net; ppravin012@gmail.com

How to cite this article: Potdar PD. Circulating tumor cells: hope to diagnose and treat metastatic cancer. J Cancer Metastasis Treat 2017;3:1-5.

Article history: Received: 19-12-2016 Accepted: 22-12-2016 Published: 12-01-2017

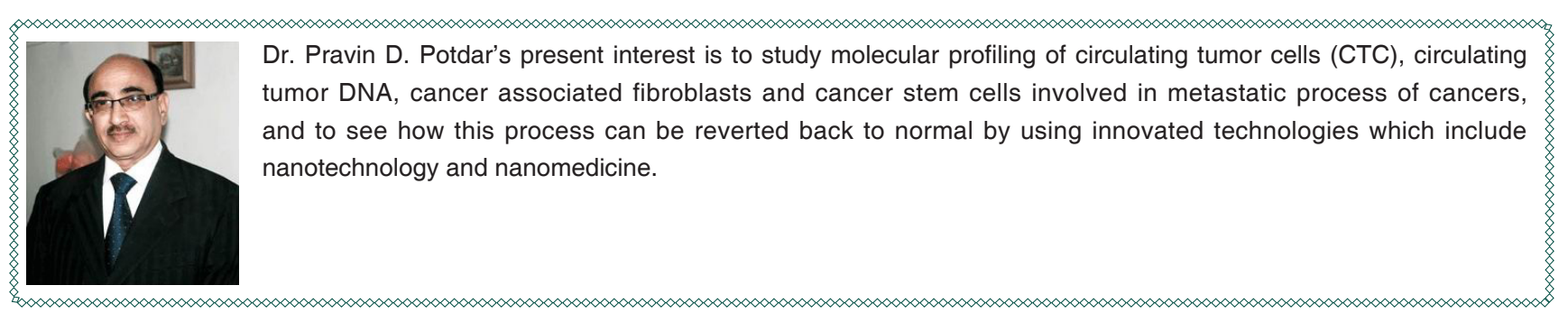

\section{CHARACTERISTICS OF CIRCULATING TUMOR CELLS}

In 1869, Thomas Ashworth, an Australian physician, for the first time observed the cells which are morphologically identical to cancer cells in the blood circulation of metastatic cancer patients. Today, these cells are known as circulating tumor cells (CTCs). ${ }^{[1]}$ Since most cancer deaths are associated with metastases, there is a need to study the exact mechanism of this cancer spread.

Until recently, primary biopsy has been the basis of cancer diagnosis, as it has been difficult to develop a research or diagnostic test based on Thomas Ashworth's finding. The major reason for this is the extremely small number $(6-10)$ of CTCs in the bloodstream, and their heterogeneity affecting their cell surface markers in isolation. However, tissue biopsies have limited effectiveness as a diagnostic tool because they are invasive and not suited to repeated sampling; biopsies also cannot monitor the treatment of metastatic cancer patients during therapy. Analysis of CTCs analysis is non-invasive and can be carried out easily in combination with available liquid biopsies such as blood and body fluids of metastatic cancer patients. Multiple samples can also be made available to monitor treatment protocols of metastatic cancer patients during therapy. In addition, CTCs analysis allows clinicians to monitor disease progression over a period of time and provide appropriate treatment modification in a patient's therapy, thus improving the patient's prognosis and quality of life. 
The CTCs are simply shredded tumor cells from the original tumor which enter blood circulation and form secondary tumor growth at several sites, featuring the suitable environment shown in Figure 1. The CTCs are large cells with large nuclei and a granular cytoplasm with a very specific spike-like appearance on the surface of each cell. ${ }^{[2]}$ It is presumed that these spike-like processes help these cells to adhere to blood vessels and promote the metastatic, invasive progress of cancer.

The CTCs are confirmed to be cancer cells with expressed cytokeratin (CK) as a marker for the epithelial origin of tumors, but these cells do not express a CD45 marker indicating that they do not have a hematopoietic origin. ${ }^{[3]}$ During the cancer metastatic process, CTCs undergo several epithelial mesenchymal transitions (EMT) and lose their CK and epithelial cell adhesion molecule (EpCAM) molecule on their surface. These CTCs may be considered resistant to chemo- and radiotherapies and are suggestive of highly metastatic tumors. Often, CTCs are found in clusters. These clusters have cancer-specific biomarkers indicative of increased metastatic risk and poor prognosis. ${ }^{[4]}$

\section{CTCS AND SOLID TUMOR MALIGNANCIES}

As circulating tumor cell analysis is a non-invasive process, it is very useful in diagnosis and monitoring of solid tumor malignancies. Most solid tumors such as breast, ovarian, lung, prostate, pancreatic, and colon cancers are mainly developed inside the body and many times are only diagnosed at the last stage of cancer development. Such tumor analysis can presently be done by tissue biopsies which are invasive and cannot be repeated at intervals for monitoring cancer therapies. Liquid biopsies can be available at any time during chemo- or radiotherapy treatment and can help clinicians in understanding the response of drug therapies, which can be altered in individual cancer patients as per their response to treatment. Therefore, CTCs analysis is useful in diagnosis and management of therapies of solid tumor malignancies, as shown in Figure 2.

\section{ENUMERATION OF CTCS IN CANCER DIAGNOSIS AND THERAPIES}

Enumeration of CTCs has great importance in prognostic and therapeutic cancer treatment; however, due to the very small number of CTCs in blood circulation, these cells are difficult to isolate and quantitate accurately. So far it has been reported that only $0.01 \%$ cells are present in metastatic cancer patients and the frequencies of circulating tumor cell vary from 1 to 10 cells $/ \mathrm{mL}$ of whole blood in patients with metastatic cancer. So far, CTCs have been detected in several epithelial cancers including breast, prostate, lung, and colon cancer, as shown in Figure 2. Similarly, enumeration of CTCs can describe the level of metastatic potential in malignant tumors and suggest the appropriate treatment to manage this disease.

Another major problem in isolation of CTCs is the change in their surface markers during the EMT phase. Many CTCs lose their surface CK19 and EpCAP proteins during EMT and thus it is very difficult to use even the FDA-approved "Cell Search Kit" in this situation. ${ }^{[5]}$ It has been generally observed that most CTCs enter into the EMT phase in highly metastatic

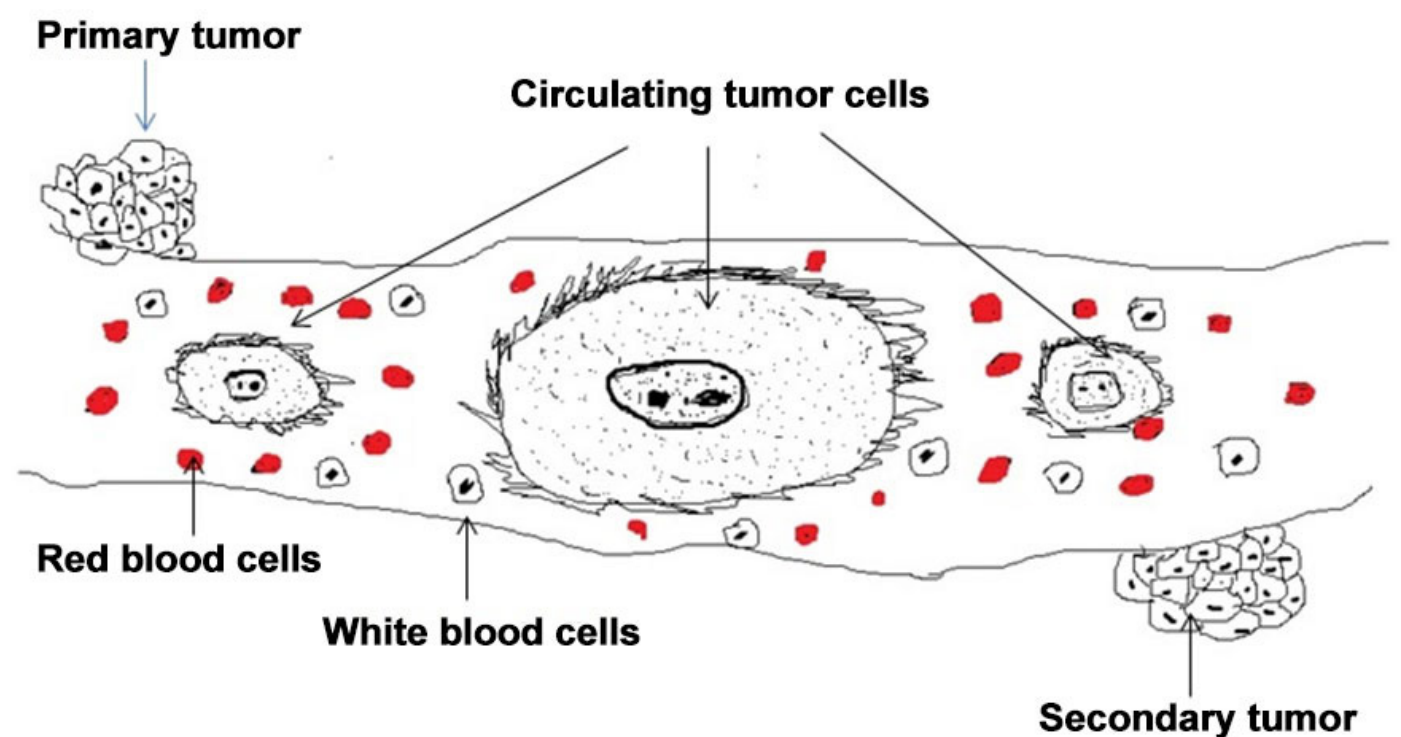

Figure 1: Large oval-shaped CTCs with spikes on their surface in the blood circulation of a metastatic cancer patient; these CTCs are shredded from the original tumor and subsequently form a secondary tumor at a different site. CTCs: circulating tumor cells 


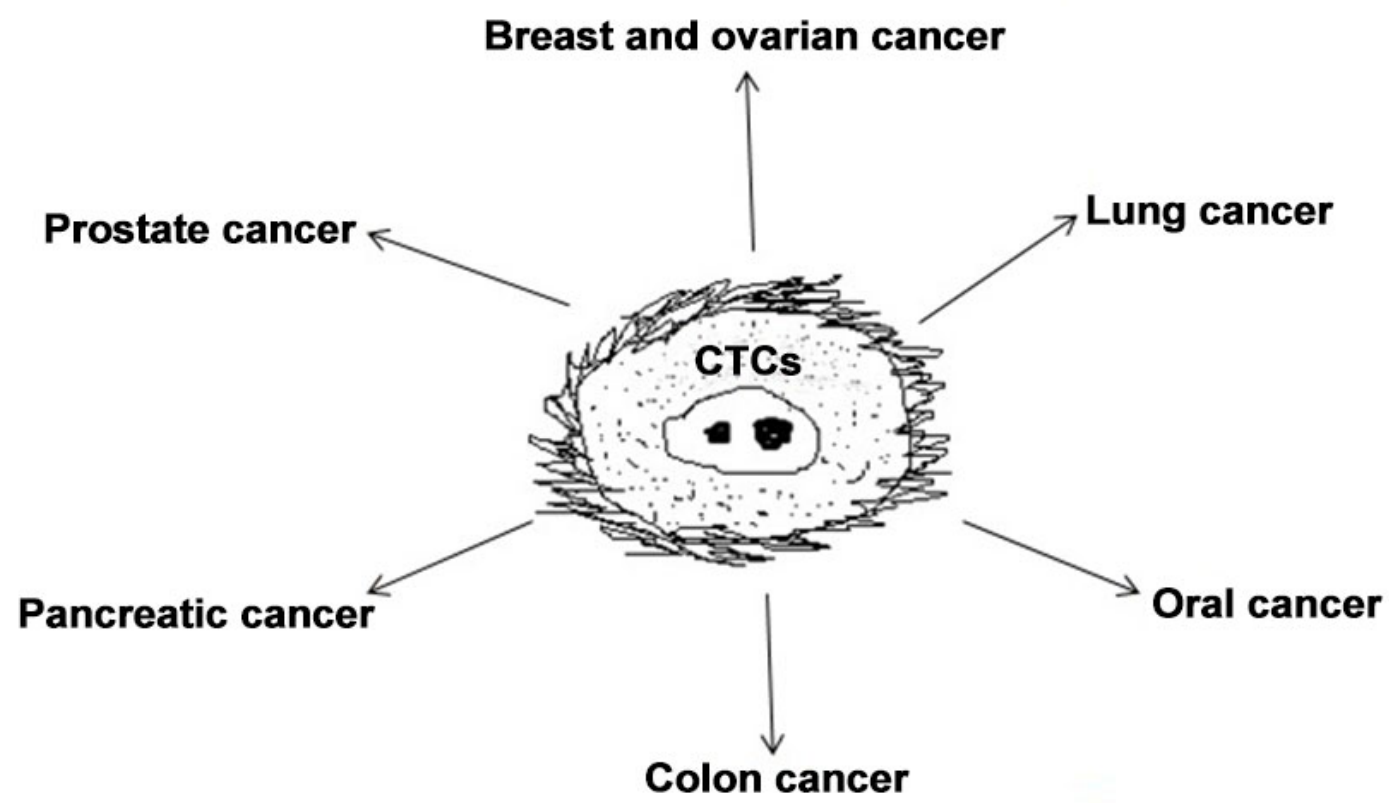

Figure 2: Circulating tumor cells analysis in several epithelial cancers including breast, prostate, lung and colon cancer. CTCs: circulating tumor cells

tumors and thus cannot be separated using the Cell Search Kit. Besides this kit, various CTC isolation methods are being established to isolate CTCs from liquid biopsies, including the Ficoll Gradient Method, the Islet Method, the Microfluidic Method and others. It is a very important task for cancer scientists to establish a precise method for isolation of CTCs from liquid biopsies, taking into consideration their EMT phase and surface marker alterations during metastatic process.

\section{MOLECULAR PROFILING OF CTCS}

The CTCs can undergo a variety of changes during the metastatic process and show heterogeneous characteristics, causing difficulties in giving proper treatment to cancer patients. Therefore, there is a need to well characterize these isolated cells by gene expression profiling. Molecular profiling of CTCs is therefore an integral part of CTCs analysis and provides accurate phenotypes of these cancer cells. ${ }^{[6]}$ So far it is well established that certain genes are upregulated, downregulated or mutated in several solid tumor malignancies and their analysis can help in proposing targeted therapies to treat many of these cancers. A major phenomenon seen in CTCs in metastatic cancer is their transformation during EMT transition. During the EMT process, CTC cells go through several modifications at both cellular and molecular levels. ${ }^{[7]}$ There is downregulation of E-cadherin genes and upregulation of TWIST1 and TWIST1 genes. In addition, there is an upregulation of extracellular matrix proteins such as vimentin and fibronectin which are responsible for invasive processes. ${ }^{[8]}$

The CTCs are extensively studied in the diagnosis and treatment of breast cancer. Molecular profiling of CTCs shows the progression of breast cancer and its response to therapy. ${ }^{[9]}$ Swaby et al. ${ }^{[10]}$ have described HER2- breast cancer patients with HER2+ CTCs who were given a trastuzumab-based therapy. This led to a considerable revision in their treatment protocol and proved that CTCs profiling is very important in identification of the most useful therapy in HER2- breast cancer patients. The CK19 and TP53 gene mutation can also reveal the metastatic potential of triplenegative breast cancer patients. In prostate cancer, expression of the fusion of TMPRSS2 and ERG genes and downregulation of PTEN have been shown to be responsible for cancer causation. ${ }^{[11]}$ Schölch et al. ${ }^{[12]}$ have discovered a KRAS mutation in the CTCs of CRC patients whose primary tumor was KRAS wild-type, suggesting that the sequence analysis of CTCs can better discover the presence of KRAS mutation.

Treatment of other cancers can also benefit from CTCs analysis. This analysis is especially useful in lung cancer because repeated biopsies are not possible in these patients. Evaluating mutations on exon 19 and 21 of the EGFR gene are the prime determinant for drug-based therapies in lung cancer. In addition, mutations such as T790M, EML4-ALK rearrangement, BRAF, KRAS, HER2, PIK3CA/AKT1, ROS, FGFR1, and MET can all be studied for lung cancer treatment. ${ }^{[13]}$ Overexpression of H-RAS oncogene and 
mutations in FGR-R genes in CTCs can be considered as a diagnostic marker in bladder cancer. Similarly, TWIST and vimentin are considered as diagnostic markers for hepatocellular carcinoma. Häfner et al. ${ }^{[14]}$ have isolated CTCs from metastatic cervical cancer patients and evaluated levels of HPV16-E6 mRNA by real-time PCR, as a more sensitive molecular marker than CK19 mRNA. At the same time, Kuhlmann et al. ${ }^{[15]}$ have shown that ERCC1+ CTCs can predict platinum resistance therapy in ovarian cancer. Overall, it seems that molecular profiling of CTCs is becoming a popular tool for diagnosis and therapies of solid tumor malignancies.

\section{CLINICAL APPLICATIONS OF CTCS ANALYSIS}

Recently, analysis of CTCs in the blood of metastatic cancer patients has received enormous attention because of its very important clinical applications in personalized medicine. ${ }^{[16]}$ Several investigators have studied CTCs derived from breast cancer patients for diagnosis and treatment of breast cancer. They have shown direct correlation of CTCs with disease prognosis and survival, and shown that the greater the number of CTCs, the lower the chances of survival. The CellSearch ${ }^{\circledR}$ system, FDA-approved, is most commonly used for enumeration of CTCs in these experiments, which are mainly based on positive expression of EpCAM and CK protein on the surface of these cells. ${ }^{[17]}$ However, this may limit the selection due to the EMT transition process undergoing in CTCs during the metastatic process of cancer, in which there is a downregulation of EpCAM surface protein. The CTCs values are measured before and after chemoor radiotherapies and treatment can be determined by greater or lesser CTCs counts in patients. Peeters et al. ${ }^{[18]}$ have shown that patients with more than 80 CTCs in $7.5 \mathrm{~mL}$ blood died within one year following diagnosis of metastases. ${ }^{[18]}$ CTCs analysis is very much useful in understanding stages of various cancers. Overall this suggests that CTCs enumeration and molecular profiling with proper follow-up can determine the aggressiveness of cancers, which could help clinicians decide more efficacious and targeted treatments for management of metastatic cancer patients.

\section{Financial support and sponsorship}

Nil.

\section{Conflicts of interest}

There are no conflicts of interest.

\section{Patient consent}

There is no patient involved.

\section{Ethics approval}

This article does not contain any studies with human participants or animals.

\section{REFERENCES}

1. Ashworth TR. A case of cancer in which cells similar to those in the tumors were seen in the blood after death. Aus Med J 1869;14:146-9.

2. Racila E, Euhus D, Weiss AJ, Rao C, McConnell J, Terstappen LW, Uhr JW. Detection and characterization of carcinoma cells in the blood. Proc Natl Acad Sci U S A 1998;95:4589-94.

3. Marrinucci D, Bethel K, Kolatkar A, Luttgen MS, Malchiodi M, Baehring F, Voigt K, Lazar D, Nieva J, Bazhenova L, Ko AH, Korn WM, Schram E, Coward M, Yang X, Metzner T, Lamy R, Honnatti M, Yoshioka C, Kunken J, Petrova Y, Sok D, Nelson D, Kuhn P. Fluid biopsy in patients with metastatic prostate, pancreatic and breast cancers. Phys Biol 2012;9:016003.

4. Aceto N, Bardia A, Miyamoto DT, Donaldson MC, Wittner BS, Spencer JA, Yu M, Pely A, Engstrom A, Zhu H, Brannigan BW, Kapur R, Stott SL, Shioda T, Ramaswamy S, Ting DT, Lin CP, Toner M, Haber DA, Maheswaran S. Circulating tumor cell clusters are oligo clonal precursors of breast cancer metastasis. Cell 2014;158:1110-22.

5. Mikolajczyk SD, Millar LS, Tsinberg P, Coutts SM, Zomorrodi M, Pham T, Bischoff FZ, Pircher TJ. Detection of EpCAM-negative and cytokeratin-negative circulating tumor cells in peripheral blood. $J$ Oncol 2011;2011:252361.

6. Potdar PD, Lotey NK. Review: circulating tumor cells in future diagnosis and therapies of cancer. J Cancer Metastasis Treat 2015;1:44-56.

7. Krawczyk N, Meier-Stiegen F, Banys M, Neubauer H, Ruckhaeberle E, Fehm T. Expression of stem cell and epithelial-mesenchymal transition markers in circulating tumor cells of breast cancer patients. Biomed Res Int 2014;2014:415721.

8. Chen CL, Osmulski P, Mahalingum D, Horning AM, Jadhav RR, Louie AD, Wang CM, Huang THM. Abstract 5588: epithelial-tomesenchymal markers of circulating tumour cells for detection of castration-resistant prostate cancer. Cancer Res 2014;74:5588.

9. Aceto N, Bardia A, Miyamoto DT, Donaldson MC, Wittner BS, Spencer JA, Yu M, Pely A, Engstrom A, Zhu H, Brannigan BW, Kapur R, Stott SL, Shioda T, Ramaswamy S, Ting DT, Lin CP, Toner M, Haber DA, Maheswaran S. Circulating tumour cell clusters are oligoclonal precursors of breast cancer metastasis. Cell 2014;158:1110-22.

10. Swaby RF, Cristofanilli M. Circulating tumor cells in breast cancer: a tool whose time has come of age. BMC Med 2011;9:43.

11. Dittamore R, Louw J, Krupa R, Anand A, Danila DC, ArslanZ, Bales N, Marrinucci D, Scher HI. Molecular characterization of circulating tumour cells (CTC) and CTC subpopulations in baseline and progressive metastatic castration resistant prostate cancer (mCRPC). J Clin Oncol 2014;32:e16018.

12. Schölch S, Bork U, Rahbari NN, García S, Swiersy A, Betzler AM, Weitz J, Koch M. Circulating tumor cells of colorectal cancer. Cancer Cell Microenviron 2014;1:1-5.

13. Hodgkinson CL, Morrow CJ, Li Y, Metcalf RL, Rothwell DG, Trapani F, Polanski R, Burt DJ, Simpson KL, Morris K, Pepper SD, Nonaka D, Greystoke A, Kelly P, Bola B, Krebs MG, Antonello J, Ayub M, Faulkner S, Priest L, Carter L, Tate C, Miller CJ, Blackhall F, Brady G, Dive C. Tumorigenicity and genetic profiling of circulating tumor cells in small-cell lung cancer. Nat Med 2014;20:897-903.

14. Häfner N, Gajda M, Altgassen C, Hertel H, Greinke C, Hillemanns P, Schneider A, Dürst M. HPV16-E6 mRNA is superior to cytokeratin 19 mRNA as a molecular marker for the detection of disseminated tumour cells in sentinel lymph nodes of patients with cervical cancer by quantitative reverse-transcription PCR. Int J Cancer 2007;120:1842-6. 
15. Kuhlmann JD, Wimberger P, Bankfalvi A, Keller T, Schöler S, Aktas B, Buderath P, Hauch S, Otterbach F, Kimmig R, Kasimir-Bauer S. ERCC1-positive circulating tumor cells in the blood of ovarian cancer patients as a predictive biomarker for platinum resistance. Clin Chem 2014;60:1282-9.

16. Alix-Panabières $\mathrm{C}$, Pantel K. Clinical applications of circulating tumor cells and circulating tumor DNA as liquid biopsy. Cancer Discov 2016;6:479-91.

17. Rack B, Schindlbeck C, Jückstock J, Andergassen U, Hepp P, Zwingers T, Friedl TW, Lorenz R, Tesch H, Fasching PA, Fehm T,
Schneeweiss A, Lichtenegger W, Beckmann MW, Friese K, Pantel K, Janni W; SUCCESS Study Group. Circulating tumor cells predict survival in early average-to-high risk breast cancer patients. $J$ Natl Cancer Inst 2014;106:dju066.

18. Peeters DJ, van Dam PJ, Van den Eynden GG, Rutten A, Wuyts H, Pouillon L, Peeters M, Pauwels P, Van Laere SJ, van Dam PA, Vermeulen PB, Dirix LY. Detection and prognostic significance of circulating tumour cells in patients with metastatic breast cancer according to immunohistochemical subtypes. $\mathrm{Br} \mathrm{J}$ Cancer 2014; $110: 375-83$ 